The University of Southern Mississippi The Aquila Digital Community

Faculty Publications

$12-18-2017$

\title{
Alcohol Priming and Attribution of Blame in an Acquaintance Rape Vignette
}

Elena V. Stepanova

University of Southern Mississippi, elena.stepanova@usm.edu

Amy L. Brown

University of Louisiana at Lafayette

Follow this and additional works at: https://aquila.usm.edu/fac_pubs

Part of the Psychology Commons

\section{Recommended Citation}

Stepanova, E. V., Brown, A. L. (2017). Alcohol Priming and Attribution of Blame in an Acquaintance Rape Vignette. Journal of Interpersonal Violence.

Available at: https://aquila.usm.edu/fac_pubs/16567

This Article is brought to you for free and open access by The Aquila Digital Community. It has been accepted for inclusion in Faculty Publications by an authorized administrator of The Aquila Digital Community. For more information, please contact Joshua.Cromwell@usm.edu. 


\begin{abstract}
Research on non-pharmacological effects of alcohol shows that exposure to alcohol-related cues (i.e., alcohol priming) can increase behaviors associated with actual alcohol consumption. Attributions of responsibility to female victims in sexual assault scenarios are affected by whether or not alcohol was consumed by a victim or/and perpetrator. Victims often receive higher levels of blame if they consume alcohol prior to the assault. This work extends the research on non-pharmacological effects of alcohol into a novel domain of blame attribution toward rape victims. In two studies, participants in lab settings (Study $1 ; N=184$ ) and online (Study $2 ; N=421$ ) were primed with alcohol or neutral beverage advertisements as part of a purportedly separate ad-rating task and then were presented with a vignette depicting an acquaintance rape where the characters consumed beer or soda. Participants subsequently completed a questionnaire assessing victim blame and perpetrator blame. Across both studies, participants blamed the victim most when they were exposed to both contextual (story) and noncontextual (ads) alcohol cues; this effect was especially prominent in males in Study 1. Findings for perpetrator blame were inconsistent across studies. Implications of non-pharmacological effects of alcohol on blame attribution toward rape victims are discussed in the context of courtroom situations and bystander intervention.
\end{abstract}

Keywords: alcohol priming, alcohol use, rape, victim blame, disinhibition

Stepanova, E. V. \& Brown, A. L. (in press). Alcohol priming and blame attribution in an acquaintance rape vignette. Journal of Interpersonal Violence. doi:10.1177/0886260517744762 


\section{Alcohol Priming and Attribution of Blame in an Acquaintance Rape Vignette}

Alcohol plays an important and complex role in sexual victimization. Alcohol use is a risk factor for both victimization and perpetration (e.g., Abbey, Wegner, Woerner, Pegram, \& Pierce, 2014; Carey, Durney, Shepardson, \& Carey, 2015; Krahé et al., 2015; Smith, Homish, Leonard, \& Cornelius, 2012) and the majority of sexual assaults among college students involve alcohol consumption by the perpetrator, victim, or both (Abbey, 2002; Abbey et al., 2014; Lawyer, Resnick, Bakanic, Burkett, \& Kilpatrick, 2010; Mohler-Kuo, Dowdall, Koss \& Wechsler, 2004, White \& Hingson, 2014). Research on judgments of victims and perpetrators shows that alcohol impacts how characters in hypothetical scenarios are judged; in scenarios where a woman consumed alcohol prior to being raped, the woman is often judged as less credible/more responsible (and the man is seen as less responsible) than in scenarios where the victim was sober (Brown, Horton, \& Guillory, in press; Grubb \& Turner, 2012; Krahé, Temkin, \& Bieneck, 2006; Sims, Noel, \& Maisto, 2007; Stormo, Lang, \& Stritzke, 1997). Furthermore, when participants consume alcohol prior to being exposed to scenarios containing sexual aggression, they are likely to judge (a) the female character as higher in sexual arousal and (b) the male character's behavior as more appropriate, compared to non-drinking participants (Abbey, Buck, Zawaski, \& Saenz, 2003; Gross, Bennett, Sloan, Marx, \& Juergens, 2001). This pattern of results suggests that alcohol can activate schema-driven informationprocessing, including beliefs that women desire and precipitate rape (Krahé et al., 2006). Further support for this notion comes from research showing that the mere expectation that one has consumed alcohol (via placebo-control conditions in alcohol administration studies) activates relevant cognitions and behaviors (Testa et al., 2006). In other words, people who believe that alcohol increases sexual arousal may become aroused after believing they have consumed 
alcohol, even when they did not actually consume any alcohol (George, Stoner, Norris, Lopez, \& Lehman, 2000).

Research on alcohol priming shows that exposure to alcohol-related cues such as alcoholrelated images or words (in the absence of alcohol consumption) can increase sexual attraction, even when those cues are presented outside of conscious awareness (Friedman, McCarthy, Forster, \& Denzler, 2005). Other work has shown that exposure to alcohol cues stimulates various disinhibited judgments and behaviors such as aggression (e.g., Bartholow \& Heinz, 2006; Friedman, McCarthy, Bartholow, \& Hicks, 2007; Subra, Muller, Begue, Bushman, \& Delmas, 2010), expression of racial biases (Stepanova, Bartholow, Saults, \& Friedman, 2012, in press), and negative biases toward lesbians and gay men (Greitemeyer \& Nierula, 2016). Importantly, exposure to alcohol-related cues in the environment produces similar social disinhibition effects to those that result from actual alcohol consumption (Freeman, Friedman, Bartholow, \& Wulfert, 2010). Freeman et al. reported that participants exposed to images of alcoholic beverages (as opposed to control beverages) were faster to respond to provocative words (i.e., words related to sex and bodily waste) than to neutral words in a free-association task. Thus, exposure to alcohol-related cues influences a host of behaviors in ways consistent with consumption, but for reasons differing from alcohol's pharmacological effects. Specifically, such exposure to alcohol-related cues activates either explicit alcohol expectancies - beliefs about effects alcohol has on one's and others behavior (see Goldman, Darkes, \& Del Boca, 1999) or implicit memory associations - associations formed by previous direct and indirect experiences with alcohol (Stacy, 1995). Subsequently, activation of either explicit expectancies or implicit memory associations triggers relevant behaviors to emerge, which is consistent with work on priming of behavioral scripts in social psychology (e.g., Bargh, Schwader, Hailey, Dyer, \& Boothby, 2012; Molden, 2014). 
The goal of this work was to extend previous research on alcohol priming into a new domain of judgment of rape victims and perpetrators. The current study explored the extent to which exposure to non-contextual and contextual types of alcohol cues would affect attributions of responsibility to the victim and perpetrator in an acquaintance rape vignette. This research has potential important implications for how people think about and respond to rape victims. On the one hand, knowing that a victim consumed alcohol prior to being raped can increase attributions of blame and reduce culpability judgments of perpetrators, which could influence juries in rape trials (Grubb \& Turner, 2012). However, if non-contextual alcohol cues impact victim blame, like they do other social judgments (e.g., perception of others' hostility, Bartholow \& Heinz, 2006, Experiment 2; Pedersen, Vasquez, Bartholow, Grosvenor, \& Truong, 2014), then exposure to thoughts or images of alcohol (e.g., by reading a magazine/watching television commercials or when receiving information that a rape occurred in an alcohol-rich environment) could impact jurors even in cases where the victim was not reportedly drinking. More directly, alcohol cues can impact bystanders who might otherwise be in a position to prevent sexual violence (Burn, 2009). The bystander approach (e.g., Bannon \& Foubert, 2017; Banyard, Moynihan, \& Plante, 2007; Exner \& Cummings, 2011) is an increasingly common educational strategy to reduce the incidence of sexual violence; however, little is yet known about the impact of alcohol on bystanders (Fleming \& Wiersma-Mosley, 2015). Burn (2009) suggested that intoxicated victims could be seen as less worthy of bystander intervention, a theme also implied by focus group participants in a study by Koelsch, Brown, and Boisen (2012). Because sexual assault among college students often occurs in the context of bars or parties (Lawyer et al., 2010), opportunities for bystanders to get involved likewise will often occur in situations where alcohol is being consumed. As such, the presence of alcohol cues in the environment could impact the 
willingness of bystanders to intervene in instances of potential sexual violence, regardless of whether or not the potential victim had been drinking.

In the current studies, non-contextual alcohol cues were manipulated by presenting participants with pictorial advertisements of alcoholic or non-alcoholic beverages (Picture Prime) as part of a purportedly separate ad-rating task in a lab setting (Study 1) or online (Study 2). Contextual alcohol cues were manipulated by presenting a vignette depicting an acquaintance rape in which the characters were described as having consumed beer or soda (Story Prime). We hypothesized that participants primed with non-contextual alcohol-related cues would attribute more responsibility to the victim than participants not primed with alcohol cues. We also expected that participants would blame the victim more when the characters consumed alcohol than when they did not. We expected that the highest levels of victim blame would occur when participants were primed with both contextual and non-contextual alcohol-related cues.

We expected to get the opposite results for the perpetrator blame. We hypothesized that participants primed with non-contextual alcohol-related cues would attribute less responsibility to the perpetrator than participants not primed with alcohol cues. We also expected that participants would blame the perpetrator less when the characters consumed alcohol than when they did not. We expected that the lowest levels of perpetrator blame would occur when participants were primed with both contextual and non-contextual alcohol-related cues. Because research has shown that men's judgments of rape victims are more affected by situational cues than are women's (Klippenstine, Schuller, \& Wall, 2007; Pollard, 1992; Vandiver \& Dupalo, 2012), we expected these effects described above to be stronger for men than for women.

\section{Study 1}

In this study, we tested the impact of contextual and non-contextual alcohol priming in a lab setting, utilizing computerized and paper-and-pencil administration of materials. 


\section{Method}

\section{Participants}

Participants were 187 ( 88 women, 99 men; $M$ age $=20.46, S D=5.21$ ) students from two medium-sized public universities in the South. Most participants identified as White (64\%) or Black (24\%). Participants were recruited through the on-line research participation system (SONA) at both schools. This system allowed students to earn extra credit in psychology courses for participating. Most participants recruited through SONA systems are enrolled in introductory psychology classes and thus come from a variety of majors. One hundred and eleven participants were recruited from one of the institutions first (88 women, 23 men) in 2013-2014. Subsequently, we decided to recruit more men to test for gender effects. In 2015-2016 we recruited additional male participants, 31 from one institution and 45 from the other.

Data from one participant (a male) was excluded because he failed the manipulation check regarding what the characters in the story drank; data from two additional participants (both female) were excluded because of record-keeping errors that made it impossible to determine to which picture prime condition they had been assigned. As such, analyses are based on a smaller sample $(N=184)$.

\section{Design}

The study utilized a 2 (Story Prime: coke or beer) by 2 (Picture Prime: alcohol ads or non-alcohol ads) x 2 (Gender: male or female) experimental design.

\section{Materials and Procedure}

The study was reviewed and approved by the institutional review boards at both universities. At both universities, participants completed the study in group sessions in computer labs with dividers between work stations to ensure privacy. Participants were told they would participate in two separate studies: one on Ad Ratings and one on Social Perceptions. The 
experimenter's script stated: “Our lab is running two short studies. To make it easier for us to get participants for both, and to make it easier for you all to earn credit, we are running both studies during the same session." To maintain an illusion of two separate studies, participants were told that they would complete the first study on the computer and the second study using paper questionnaires. Participants were randomly assigned to one of the four experimental conditions: the alcohol ads-beer story; the alcohol ads-coke story; the non-alcohol ads-beer story; the nonalcohol ads-coke story.

The Ad Rating task involved viewing and evaluating a series of print advertisements featuring either alcoholic on non-alcoholic beverages (see Stepanova et al., 2012). Specifically, participants were presented with either 6 alcohol beverages advertisements (non-contextual alcohol cue condition) or 6 non-alcoholic beverage advertisements (non-contextual non-alcoholic cue condition). All advertisements were taken from printed magazines (see Stepanova et al., 2012 for details). Advertisements were presented in random order, one at a time. Participants rated each ad on several dimensions using a scale ranging from 1 (Not at all) to 7 (Extremely). Participants were asked the following questions: How pleasing did you find this ad? How interesting did you find this ad? How persuasive did you find the ad? How clear was the ad's message? How likely would you be to purchase this product? Each advertisement was displayed until a participant completed all five ratings.

The Social Perception task involved reading a story about two students' (Jessica and Kevin) experience at and immediately after a party. Jessica and Kevin are described as friends who may have feelings for each other; it is stated that Jessica is not sure she is ready to become romantically involved with Kevin. The story described Jessica and Kevin as drinking either several cokes or several beers at the party (a precise number is not given, nor is it stated whether either became intoxicated in the version featuring alcoholic beverage consumption). Both 
versions of the story ended with Kevin forcing sex upon Jessica against her will. All print advertisements and full text of the story are available at https://www.dropbox.com/s/x0y52k15tok7r7j/Supplementary-Materials_Anonymous.docx?dl=0

After reading the story, participants answered 14 follow-up questions. The first two questions were manipulation checks about the event that Jessica and Kevin attended and about what they drank while there. One participant from the coke story prime condition who responded with "alcoholic beverages" was eliminated from analyses. Participants then answered several questions (on 1-7 scales) about the characters in the story. Three items assessed victim blame ( $\alpha$ $=.64 ; M=2.67, S D=1.15$ ): How appropriate were Jessica's actions? (from Not at all appropriate to Very appropriate); To what extent did Jessica's behaviors contribute to the outcome of the story? (from Not at all to Very much); How responsible is Jessica for what happened at the end of the story? (from Not at all responsible to Very responsible). Three items assessed perpetrator blame $(\alpha=.56 ; M=6.65, S D=.61)^{1}$ with the analogous wording (Kevin was substituted for Jessica). Four additional questions assessed each character's attraction to and sexual desire for the other character ${ }^{2}$.

After completing the follow-up questionnaire, participants completed three subscales (Arousal/Aggression, Sexual Enhancement, and Social Assertiveness) from the Alcohol Expectancy Questionnaire (AEQ; Goldman, Greenbaum, \& Darkes, 1997); however, this was measured only for exploratory purposes, and thus will not be discussed any further. Finally, participants completed a questionnaire assessing their alcohol use history and demographic information. Specifically, participants were asked to indicate their gender, age, ethnicity, and year in school. They indicated whether or not they drink at least occasionally, and those who indicated at least occasional drinking completed the daily drinking questionnaire (Collins, Parks, \& Marlatt, 1985), an assessment of typical drinking behavior during a typical week over the past 
month. Only gender was analyzed as a variable in the current study; other demographic and drinking data are reported for descriptive purposes only.

The AEQ and demographic/drinking behavior questionnaires were assessed at the end of the session to avoid priming participants in no-alcohol-cue conditions with thoughts of alcohol. Participants then received a written debriefing and were dismissed.

\section{Data Analysis Approach}

Multiple problems associated with null hypothesis significance testing (NHST) have been reported (e.g., Abelson, 1997; Cumming, 2014; Loftus, 1996; Trafimow, 2003). Valentine, Aloe, and Lau (2015) summarize such criticisms: (a) there are multiple misconceptions as to what NHST results signify; (b) NHST "obscures...indicators of the practical meaning of the relationship being studied" (p. 261); (c) "NSTS results in a binary reject/do not reject decision" (p. 261) with a possible outcome to reject the null with .05 but not $.051 p$ value (see Rosnow \& Rosenthal, 1989); and (d) NHST encourages publication bias (i.e., only studies reporting $p$ s < .05 get submitted and accepted), outcome reporting bias (results are reported only on measures achieving $p \mathrm{~s}<.05)$, and significance chasing through questionable research practices (e.g., Simmons, Nelson, \& Simonsohn, 2011) and research integrity violations (Ioannidis, 2005). A recent statement by the American Statistical Association cautions against relying on $p$-values to infer importance of results and sizes of effects (Wasserman \& Lazar, 2016). Given problems associated with NHST and recommendations to rely on new types of estimation statistics such as effect sizes to avoid them (e.g., Cumming, 2014; Valentine et al., 2015), our use of ANOVA modeling was to examine patterns of means, not to interpret significance levels. However, given how widespread the NSTS approach is, we provide all the associated significance tests for each of the effects reported below in Appendix A.

\section{Results}


All the analyses reported are based upon the final sample of $N=184$. Most participants (82\%) reported drinking at least occasionally. Of those who reported any alcohol consumption, the average number of drinks consumed in a typical week was $7.98(S D=10.10)$.

We performed two 2 (Story Prime: coke or beer) by 2 (Picture Prime: alcohol ads or nonalcohol ads) x 2 (Gender: male or female) analyses of variance (ANOVAs), with victim blame and perpetrator blame as dependent variables. We report effect sizes for all the effects and interactions below. First, we report results for victim blame. We found a small gender effect: men attributed more blame to the victim $(M=2.80, S D=1.21)$ than women $\operatorname{did}(M=2.55, S D=$ $1.08), d=.21$ (a small effect size). Participants in the two picture prime conditions did not differ in their victim blame attribution. Specifically, participants in the alcohol ads picture prime condition attributed similar levels of blame to the victim $(M=2.70, S D=1.15)$ as did those in the non-alcohol ads picture prime condition $(M=2.67, S D=1.16), d=.03$. However, there were differences in victim blame between story prime conditions: participants in the beer story prime condition $(M=2.84, S D=1.15)$ attributed more blame to the victim than did participants in the coke story prime condition $(M=2.52, S D=1.13), d=.28$ (a small effect size), see Table 1 .

Other gender differences emerged as indicated by Story Prime x Gender and Picture Prime x Gender interactions. Specifically, male participants who were exposed to a story where characters consumed alcohol attributed more blame to a victim than participants in the other three conditions (all $d \mathrm{~s}>.41$, small to medium effect sizes). Additionally, female participants who were exposed to the non-alcohol ads picture prime condition attributed less blame to the victim than participants in the other three conditions $(.26>|d s|>.08$, all small effect sizes).

More importantly, as we predicted, a Story Prime x Picture Prime interaction emerged. Specifically, participants blamed the victim most when they were exposed to both contextual (Picture Prime: alcohol ads) and non-contextual alcohol (Story Prime: beer vignette) cues $(M=$ 
$2.95, S D=1.11)$ than in either the alcohol ads/coke story experimental condition $(M=2.41, S D$

$=1.15),(d=.48$, a medium effect size $)$ or the no-alcohol ads/coke story condition $(M=2.61, S D$

$=1.12),(d=.31$, a small effect size $)$ and the no-alcohol ads/beer story condition $(M=2.73, S D$

$=1.20),(d=.19$, a small effect size). This interaction (and two interactions described above)

were qualified by a higher order Picture Prime x Story Prime x Gender interaction. Specifically, this effect described was especially prominent for males $(M=3.21, S D=1.16, .80>$ all $d \mathrm{~s}>.26$, effect sizes varied from small to large). Men exposed to both alcohol ads and a vignette where characters drank beer attributed the most blame to the victim.

For the perpetrator blame, we also found a small gender effect: women attributed more blame to the perpetrator $(M=6.72, S D=.49)$ than men $\operatorname{did}(M=6.60, S D=.71)(d=.18$, a small effect size). Participants who were primed with the alcohol-related ads attributed less blame to the perpetrator $(M=6.62, S D=.60)$ than those who were primed with non-alcohol advertisements $(M=6.68, S D=.64)$, but this effect was very small $(d=-.08)$. Participants who read a story where characters consumed beer attributed less blame to the perpetrator $(M=6.60$, $S D=.71)$ than those who read a story where characters consumed coke $(M=6.71, S D=.51)(d$ $=-.18$, small effect size), see Table 1 .

These main effects were qualified by a Story Prime x Gender and a Picture Prime x Gender interactions. Specifically, men attributed the least amount of blame to the perpetrator when they read a story where characters consumed beer compared to the other three conditions $(.31>|d s|>.20)$, but all effect sizes were small. Additionally, the highest attribution of blame to the perpetrator was observed in female participants who were exposed to the non-alcohol priming ads, compared to the other three conditions $(.38>d \mathrm{~s}>.37)$, and all effects sizes were small to medium.

\section{Study 2}


Study 1 demonstrated that both contextual and non-contextual alcohol cues can impact attributions of blame toward both victims and perpetrators of acquaintance rape, especially for men. However, Study 1 suffered from a fairly small sample size. Therefore, we aimed to recruit a larger sample size in hopes to replicate the findings and improve confidence in our results. Study 2 used on-line methods, but pulled from the same participant population as did Study 1.

\section{Method}

\section{Participants}

Participants were 433 students from the same two universities from which the Study 1 participants were recruited; 363 came from the first university and 70 from the second. The average age of participants was $19.93(S D=3.89)$; 197 participants reported their gender as female, 227 as male, 4 reported a gender other than male or female, and 5 failed to disclose a gender. Most participants were White $(72.1 \%)$ or Black $(22.4 \%)$ and were in their first $(63.7 \%)$ or second year $(18.2 \%)$ of school. ${ }^{3}$ The following cases were eliminated: all participants who failed to report gender (5), indicated a gender other than male of female (4), or failed the manipulation check regarding what the characters in the story drank (3), resulting in a final sample of 421 participants.

\section{Materials and Design}

The materials used in Study 2 were identical to those used in Study 1. The three victim blame items had an internal reliability of $\alpha=.66(M=2.35, S D=1.23)$; the three perpetrator blame items also had an internal reliability of $\alpha=.66(M=6.59, S D=.84)$. The design was also identical to that of Study 1.

\section{Procedure}

At both universities, participants signed up to participate in a study through SONA systems. Participants who signed up for Study 2 were pre-screened: only those who never 
participated in alcohol priming studies (including Study 1) were allowed to complete Study 2. Upon signing up, participants were redirected to a Survey Monkey web page. They were told that researchers are preparing for future research projects, and they are asked to help us design some of the measures and materials that will be used in future studies. Participants were told that they will complete two unrelated tasks: "Your first task in this survey is to look at and provide evaluations of several pictures of magazine advertisements. Your ratings will help us select ads for different conditions of a future study of consumer choices. Next, you will read a story about two college students and their experiences in a social setting. We are asking you to provide your impressions of the characters and of the story so that we can refine it for future research on social perceptions." From that point, the procedure was identical to Study 1.

\section{Results}

The analyses performed were identical to the analyses described in Study 1 (Appendix B reports significance tests for each of the effects reported below). The drinking behavior of the Study 2 sample was similar to that of the Study 1 sample: $75 \%$ of participants reported drinking alcohol at least occasionally. Of those who reported any drinking, the average number of drinks consumed per week was $8.06(S D=12.59)$.

First, we report results for victim blame. Analogously to Study 1, we found gender and story prime main effects. There was a small gender effect: men attributed more blame to the $\operatorname{victim}(M=2.53, S D=1.24)$ than women $\operatorname{did}(M=2.14 S D=1.18), d=.32$ (a small effect size $)$. There were differences in victim blame between story prime conditions: participants in the beer story prime condition $(M=2.45, S D=1.29)$ attributed more blame to the victim than did participants in the coke story prime condition $(M=2.24, S D=1.15), d=.17$ (a small effect size), see Table 2. Participants in the two picture prime conditions did not differ in their victim blame attribution: participants in the alcohol ads picture prime condition attributed similar levels 
of blame to the victim $(M=2.35, S D=1.25)$ as did those in the non-alcohol ads picture prime condition $(M=2.34, S D=1.21), d=0$.

We also replicated the Story Prime x Gender and Picture Prime x Gender interactions. Male participants who were exposed to a story where characters consumed alcohol attributed more blame to a victim than participants in the other three conditions (all $d \mathrm{~s}>.24$, small to medium effect sizes). Additionally, female participants who were exposed to the non-alcohol ads picture prime condition attributed less blame to the victim than participants in the other three conditions $(.56>|d s|>.23$, small to medium effect sizes). See Table 2 for all means and standard deviations.

The Story Prime x Picture Prime interaction was replicated as well. Specifically, participants blamed the victim most when they were exposed to both contextual (Picture Prime: alcohol ads) and non-contextual alcohol (Story Prime: beer vignette) cues $(M=2.52, S D=1.33)$ than in either the alcohol ads/coke story experimental condition $(M=2.13, S D=1.10),(d=.32$, a small effect size $)$ or the no-alcohol ads/coke story condition $(M=2.34, S D=1.20),(d=.14$, a small effect size) and the no-alcohol ads/beer story condition $(M=2.35, S D=1.22),(d=.13$, a small effect size). However, in Study 2, a higher order Picture Prime x Story Prime x Gender interaction followed a slightly different pattern than in Study 1. The highest victim blame attribution was found in men who were exposed to the no-alcohol ads/beer story condition $(M=$ $2.75, S D=1.24, .74>d s>.09$, small to medium effect sizes), followed by men who were exposed to the alcohol ads/beer story experimental condition $(M=2.63, S D=1.31, .61>d s>$ .09 , small to medium effect sizes), which is partially consistent with the results of Study 1.

Next, we report results for perpetrator blame. For perpetrator blame, the small gender effect was similar to the one obtained in Study 1: women attributed more blame to the perpetrator $(M=6.67, S D=.77)$ than men $\operatorname{did}(M=6.51, S D=.88)(d=.19$, a small effect size $)$. 
The other effects from Study 1 did not replicate in Study 2. Participants who were primed with the alcohol-related ads attributed more blame to the perpetrator $(M=6.64, S D=.75)$ than those who were primed with non-alcohol advertisements $(M=6.53, S D=.93)$, but this effect was very small $(d=.13)$. The contextual alcohol cues manipulation did not produce group differences: Participants who read a story where characters consumed beer attributed similar levels of blame to the perpetrator $(M=6.58, S D=.85)$ to those who read a story where characters consumed coke $(M=6.59, S D=.83)(d=.01)$, see Table 2.

A Picture Prime x Gender interaction emerged: the least amount of blame to the perpetrator was attributed by men when they were exposed to non-alcohol advertisements $(M=$ $6.41, S D=1.06)$ compared to the other three conditions $(.29>|d s|>.23$, small effect sizes $)$. A Picture Prime x Story Prime interaction also emerged. Lowest attributions of perpetrator blame occurred for the no-alcohol ads/coke story condition $(M=6.45, S D=1.00, .36>|d s|>.12$, small effect sizes), followed by the alcohol ads/beer story condition $(M=6.56, S D=.86, .24>|d s|>$ .07 . While lower levels of blame were expected in the alcohol ads/beer story condition and are consistent with our predictions, we are not entirely sure why in the no-alcohol ads/coke story condition participants indicated lower attributions for perpetrator blame.

\section{General Discussion}

Consistent with our predictions, both contextual and non-contextual priming of alcohol cues in an acquaintance rape vignette affected attributions of victim blame (Study 1 and Study 2), and these effects were qualified by gender of participants. We found that victim-blaming was the highest when participants were exposed to both types of alcohol cues, both contextual and non-contextual (Study 1 and Study 2), and especially so for men (Study 1).

In Study 1, the perpetrator blame attribution effects also emerged as a function of (a) gender and (b) either contextual or non-contextual cues. Men who read a vignette where 
characters consumed beer attributed the least blame to the perpetrator; and women who were exposed to the non-alcohol ads attributed the most blame to the perpetrator. Yet, we were able to only partially replicate these effects in Study 2; for example, the second lowest level of perpetrator blame was recorded in the alcohol ads/beer story condition, while other findings were inconsistent with our hypotheses and the Study 1 findings. We were surprised by the results of Study 2 being somewhat inconsistent with Study 1 regarding the findings for attributions of perpetrator blame; perhaps attributions of perpetrator blame are less sensitive to the noncontextual alcohol priming or our effects are spurious. It is important to keep in mind that while situational details might sometimes slightly alter perceptions of perpetrator blame, no matter what, it was always very high. Thus, people (at least when responding to psychology studies), seem to recognize that it is the perpetrator who is primarily responsible for an acquaintance rape. Ceiling effects of perpetrator blame attributions might make it harder to detect subtle effects of contextual and non-contextual cues. Nevertheless, given that our results for attribution of victim blame held consistent across two studies, we believe that both contextual and non-contextual alcohol cues influence such judgments.

These results are consistent with previous alcohol priming research showing that exposure to non-contextual alcohol-related cues produces similar effects that result from actual alcohol consumption, yet we extended this line of research into a completely novel domain: attributions of blame in an acquaintance rape scenario. Previous work on the alcohol priming effects showed that non-pharmacological effects of alcohol are observed in such outcomes as aggression (Bartholow \& Heinz, 2006; Friedman et al., 2007; Pedersen et al., 2014; Subra et al., 2010); perceptions of sexual attractiveness (Freidman et al., 2005); tension-reduction and social disinhibition (Freeman et al., 2010); and social biases (Greitemeyer \& Nierula, 2016; Stepanova et al., 2012). Importantly, in the domain we explored, such alcohol priming effects do not emerge 
without qualifications by other factors such as gender and/or explicit alcohol cues in the vignette (as indicated by the Picture Prime $\mathrm{x}$ Gender and the Picture Prime x Story Prime $\mathrm{x}$ Gender interactions).

We acknowledge that the effects involving our Story Prime (contextual cues) are not necessarily unique. Previous research has shown that victim intoxication is related to higher attributions of blame to the victim (Brown et al., in press; Grubb \& Turner, 2012; Krahé et al., 2006; Sims et al., 2007), and the link between victim drinking and judgments depends on the level of intoxication and whether or not the perpetrator was drinking (Norris \& Cubbins, 1992; Stormo, et al., 1997). However, our contribution is the first, to our knowledge, to show that both contextual (characters drinking alcoholic beverages in an acquaintance rape scenario) and noncontextual (showing participants alcohol-related images that are completely irrelevant to the judgment task in hand) interact to produce the strongest victim blame attributions.

The gender differences observed are consistent with previous work showing that men's judgments of rape victims are more strongly influenced by situational factors than are women's judgments (Pollard, 1992; Vandiver \& Dupalo, 2012). Situational factors are usually conceptualized as cues that participants can be aware of and that are relevant to the social judgment at hand; our contextual alcohol cues can be interpreted as such, but our non-contextual cues are definitely irrelevant to the task at hand (i.e., attributing blame to the characters). Therefore, it was even more surprising to see these subtle non-pharmacological effects of alcohol. Granted, most of the effect sizes in our work were small to medium, which is very consistent with the alcohol priming research.

Our findings may have important implications for how people think about and behave toward victims of rape. A great deal of research has already demonstrated that victims are attributed greater responsibility when rapes involve alcohol consumption (Grubb \& Turner, 
2012). The current study suggests that the very idea of alcohol could be enough to affect judgments, especially among men. Judgement may become more negative toward the victim the more alcohol is discussed in courtroom situations by eliciting alcohol-related implicit memory associations, even when the victim has not consumed any actual alcohol, but the rape was committed in an alcohol-rich environment (e.g., at a party or bar). Perhaps the most relevant implication of these findings is that efforts to encourage bystander intervention may be less effective to the extent that opportunities for intervention occur in alcohol-heavy social environments. If victims are seen as more responsible following simple exposure to alcohol cues, bystanders may be less motivated to actively intervene (Burn, 2009). Future research should investigate whether the effects of contextual and/or non-contextual alcohol cues inhibit bystander intervention and affects courtroom decisions.

This work is not without limitations. First, the alcohol cues we used in the picture prime condition were pictorial. Future studies can attempt to use lexical stimuli or even presentation of actual alcohol cues. Secondly, the vignettes stated that both characters either consumed beer or coke, but did not suggest how intoxicated they became. Furthermore, our work might not generalize to other diverse situations and populations. Our samples suggest higher prevalence of drinking than comparable national samples of college students, both in terms of percentage of those who drink (Substance Abuse and Mental Health Services Administration National Survey on Drug Use and Health, 2015) and weekly drinking frequency (Wechsler, Molnar, Davenport, $\&$ Baer, 1999) ${ }^{4}$. The rape vignette that we employed featured a female character as a victim and a male character as a perpetrator; in the future work, gender roles can be reversed or characters of the same gender can be described. Previous research has suggested that judgments of victims and perpetrators can be influenced in different ways depending on which character is depicted as drinking and how intoxicated they are relative to one another (Ferguson \& Ireland, 2012; Finch 
\& Munro, 2005; Norris \& Cubbins, 1992; Stormo et al., 1997; United, Orchowski, Masroleo, \& Gidycz, 2012). Clearly, the role of alcohol cues on attributions of blame in rape scenarios is a complicated one. Finally, we did not assess sexual orientation of our participants, perhaps gender effects that we observed can manifest differently in heterosexual versus gay and lesbian participants. Gay and bisexual men report higher levels of sexual victimization than heterosexual men; lesbian and bisexual women report higher levels of sexual victimization than heterosexual women (Walters, Chen, \& Breiding, 2013). Personal experience with or increased awareness of sexual victimization in gay, bisexual and lesbian participants might produce a pattern of responses more in line with heterosexual women than heterosexual men (who presumably were a majority in our sample).

While this work is not without limitations, it is one of the first steps in determining complex mechanisms of alcohol priming effects. It is possible that some of the inconsistent findings in previous research regarding the effects of victim and perpetrator alcohol consumption on attributions of blame (Klippenstine et al., 2007; Norris \& Cubbins, 1992; Stormo et al., 1997; Wall \& Schuller, 2000) could be due to interactions between different types of priming and activation of various implicit memory associations. Future research will be needed to untangle these effects. A potential implication of this research is that subtle and not-so-subtle alcohol cues can be used by men, perhaps unconsciously and automatically, to shift blame away from the perpetrator and toward the victim in a rape situation. Efforts should be made to make sure blame is placed where it belongs, even in situations involving the presence of alcohol cues. 


\section{References}

Abbey, A. (2002). Alcohol-related sexual assault: A common problem among college students. Journal of Studies on Alcohol, Suppl. 14, 118-128.

doi:10.15288/jsas.2002.s14.118

Abbey, A., Buck, P. O., Zawacki, T., \& Saenz, C. (2003). Alcohol's effects on perceptions of a potential date rape. Journal of Studies on Alcohol, 64(5), 69-677. doi:10.15288/jsa.2003.64.669

Abbey, A., Wegner, R., Woerner, J., Pegram, S. E., \& Pierce, J. (2014). Review of survey and experimental research that examines the relationship between alcohol consumption and men's sexual aggression Perpetration. Trauma, Violence \& Abuse, 15(4), 265-282. doi: $10.1177 / 1524838014521031$

Abelson, R. P. (1997). On the surprising longevity of flogged horses: Why there is a case for the significance test. Psychological Science, 8, 12-15. doi:10.1111=j.14679280.1997.tb00536.x

Bannon, R. S., \& Foubert, J. D. (2017). The bystander approach to sexual assault risk reduction: Effects on risk recognition, perceived self-efficacy, and protective behavior. Violence and Victims, 32(1), 46-59. doi:10.1891/0886-6708.VV-D-15-00057

Banyard, V.L., Moynihan, M.M., \& Plante, E.G. (2007). Sexual violence prevention through bystander education: An experimental evaluation. Journal of Community Psychology, 35(4), 463-481. doi: 10.1002/jcop.20159.

Bargh, J. A., Schwader, K. L., Hailey, S. E., Dyer, R. L., \& Boothby, E. J. (2012). Automaticity in social-cognitive processes. Trends in Cognitive Sciences, 16(12), 593-605. doi:10.1016/j.tics.2012.10.002

Bartholow, B., \& Heinz, A. (2006). Alcohol and aggression without consumption: Alcohol 
cues, aggressive thoughts, and hostile perception bias. Psychological Science, 17(1), 3037. doi:10.1111/j.1467-9280.2005.01661.x.

Brown, A. L., Horton, J., \& Guillory, A. (in press). The impact of victim alcohol consumption and perpetrator use of force on perceptions in an acquaintance rape vignette. Violence and Victims.

Burn, S. M. (2009). A situational model of sexual assault prevention through bystander intervention. Sex Roles, 60, 779-792. doi: 10.1007/s11199-008-9581-5

Carey, K. B., Durney, S. E., Shepardson, R. L., \& Carey, M. P. (2015). Precollege predictors of incapacitated rape among female students in their first year of college. Journal of Studies on Alcohol and Drugs, 76, 829-837. doi: 10.15288/jsad.2015.76.829

Cho, E., \& Kim, S. (2015). Cronbach's coefficient alpha: Well known but poorly understood. Organizational Research Methods, 18(2), 207-230.

doi:10.1177/1094428114555994

Collins, R.L., Parks, G.A., \& Marlatt, G.A. (1985). Social determinants of alcohol consumption: The effects of social interaction and model status on the self-administration of alcohol. Journal of Consulting and Clinical Psychology, 53, 189-200. doi:10.1037/0022$\underline{006 X .53 .2 .189}$

Cumming, G. (2014). The new statistics: Why and how. Psychological Science, 25, 7-29. doi: $10.1177=0956797613504966$

Exner, D., \& Cummings, N. (2011). Implications for sexual assault prevention: College students as prosocial bystanders. Journal of American College Health, 59(7), 655-657. doi:10.1080/07448481.2010.515633 
Ferguson, K., \& Ireland, C. (2012). Attitudes towards victims and perpetrators of hypothetical rape scenarios involving intoxication: An application to the UK. Journal of Aggression, Conflict and Peace Research, 4(2), 96-107. doi:10.1108/17596591211208300

Finch, E., \& Munro, V. E. (2005). Juror stereotypes and blame attribution in rape cases involving intoxicants: The findings of a pilot study. British Journal of Criminology, 45(1), 25-38. doi:10.1093/bjc/azh055

Freeman, N., Friedman, R., Bartholow, B., \& Wulfert, E. (2010). Effects of alcohol priming on social disinhibition. Experimental and Clinical Psychopharmacology, 18(2), 135-144. doi:10.1037/a0018871.

Friedman, R., McCarthy, D., Bartholow, B., \& Hicks, J. (2007). Interactive effects of alcohol outcome expectancies and alcohol cues on nonconsumptive behavior. Experimental and Clinical Psychopharmacology, 15(1), 102-114. doi:10.1037/1064-1297.15.1.102.

Friedman, R.S., McCarthy, D.M., Forster, J, \& Denzler, M. (2005). Automatic effects of alcohol cues on sexual attraction. Addiction, 100, 672-681. doi:10.1111/j.13600443.2005.01056.x.

George, W. H., Stoner, S. A., Norris, J., Lopez, P. A., \& Lehman, G. L. (2000). Alcohol expectancies and sexuality: A self-fulfilling prophecy analysis of dyadic perceptions and behavior. Journal of Studies on Alcohol, 61(1), 168-176. doi:10.15288/jsa.2000.61.168

Goldman, M. S., Darkes, J., \& Del Boca, F. K. (1999). Expectancy mediation of biopsychosocial risk for alcohol use and alcoholism. In E. I. Kirsch (Ed.), How expectancies shape experience (pp. 233-262). Washington, DC: American Psychological Association.

Goldman, M. S., Greenbaum, P. E., \& Darkes, J. (1997). A confirmatory test of hierarchical expectancy structure and predictive power: Discriminant validation of the Alcohol 
Expectancy Questionnaire. Psychological Assessment, 9, 145-157. doi: 10.1037/10403590.9.2.145

Greitemeyer, T., \& Nierula, C. (2016). Simple exposure to alcohol cues causally increases negative implicit attitudes toward lesbians and gay men. The Journal of Social Psychology, 156, 444-448. doi: 10.1080/00224545.2015.1115750

Gross, A.M., Bennett, T., Sloan, L., Marx, B.P., \& Juergens, J. (2001). The impact of alcohol and alcohol expectancies on male perceptions of female sexual arousal in a date rape analog. Experimental and Clinical Psychopharmacology, 9, 380-388. doi: 10.1037//10641297.9.4.380

Grubb, A., \& Turner, E. (2012). Attribution of blame in rape cases: A review of the impact of rape myth acceptance, gender role conformity and substance use on victim blaming. Aggression and Violent Behavior, 17, 443-452. doi: 101016/j.avb.2012.06.002

Ioannidis J. P. A. (2005). Why most published research findings are false. PLoS Medicine, 2, e124. Retrieved from http://www.plosmedicine.org/article/info:doi/10.1371/journal.pmed.0020124

Klippenstine, M.A., Schuller, R.A., \& Wall, A. M. (2007). Perceptions of sexual assault: The expression of gender differences and the impact of target alcohol consumption. Journal of Applied Social Psychology, 37, 2620-2641. doi:10.1111/j.1559-1816.2007.00273.x

Krahé, B., Berger, A., Vanwesenbeeck, I., Bianchi, G., Chliaoutakis, J., Fernández-Fuertes, A. A., \& ... Zygadło, A. (2015). Prevalence and correlates of young people’s sexual aggression perpetration and victimisation in 10 European countries: A multi-level analysis. Culture, Health \& Sexuality, 17(6), 682-699. doi:10.1080/13691058.2014.989265

Krahé, B., Temkin, J., \& Bieneck, S. (2006). Schema-driven information processing in 
judgments about rape. Applied Cognitive Psychology, 21, 601-619.doi: 10.1002/acp.1297

Lawyer, S., Resnick, H., Bakanic, V., Burkett, T., \& Kilpatrick, D. (2010). Forcible, drug facilitated, and incapacitated rape and sexual assault among undergraduate women. Journal of American College Health, 58(5), 453-460. doi:10.1080/07448480903540515

Loftus, G. R. (1996). Psychology will be a much better science when we change the way we analyze data. Current Directions in Psychological Science, 5(6), 161-171. doi:10.1111/1467-8721.ep11512376

Mohler-Kuo, M., Dowdall, G. W., Koss, M. P., \& Wechsler, H. (2004). Correlates of rape while intoxicated in a national sample of college women. Journal of Studies on Alcohol, 65(1), 37-45. doi: $10.15288 /$ jsa.2004.65.37

Molden, D. C. (2014). Understanding priming effects in social psychology: What is 'social priming' and how does it occur?. In D. C. Molden (Ed.), Understanding priming effects in social psychology (pp. 3-13). New York, NY, US: Guilford Press.

Norris, J., \& Cubbins, L.A. (1992). Dating, drinking, and rape: Effects of victim's and assailant's alcohol consumption and judgments of their behavior and traits. Psychology of Women Quarterly, 16, 179-191. doi: 10.1111/j.1471-6402.1992.tb00248.x

Nunnally, J. C. (1967). Psychometric theory. New York, NY: McGraw-Hill.

Nunnally, J. C. (1978). Psychometric theory (2nd ed.). New York, NY: McGraw-Hill.

Pedersen, W.C., Vasquez, E.A., Bartholow, B.D., Grosvenor, M., \& Truong, A. (2014). Are you insulting me? Exposure to alcohol primes increases aggression following ambiguous provocation. Personality and Social Psychology Bulletin, 40(8),1037-1049. doi: $10.1177 / 0146167214534993$

Pollard, P. (1992). Judgements about victims and attackers in depicted rapes: A review. British Journal of Social Psychology, 31, 307-326. doi: 10.1111/j.2044-8309.1992.tb00975.x 
Rosnow, R. L., \& Rosenthal, R. (1989). Statistical procedures and the justification of knowledge in psychological science. American Psychologist, 44, 1276-1284. doi:10.1037=0003066x.44.10.1276

Simmons, J. P., Nelson L. D., \& Simonsohn, U. (2011). False-positive psychology: Undisclosed flexibility in data collection and analysis allows presenting anything as significant. Psychological Science, 22, 1359-1366. doi:10.1177/0956797611417632

Sims, C. M., Noel , N. E., \& Maisto, S. A. (2007). Rape blame as a function of alcohol presence and resistance type. Addictive Behaviors, 32, 2766-2775. doi:10.1016/j.addbeh.2007.04.013

Smith, P. H., Homish, G. G., Leonard, K. E., \& Cornelius, J. R. (2012). Intimate partner violence and specific substance use disorders: Findings from the National Epidemiologic Survey on Alcohol and Related Conditions. Psychology of Addictive Behaviors, 26(2), 10.1037/a0024855. http://doi.org/10.1037/a0024855

Stepanova, E.V., Bartholow, B.D., Saults, J.S., \& Friedman, R.S. (2012). Alcohol-related cues promote automatic racial bias. Journal of Experimental Social Psychology, 48, 905-911. doi: 10.1016/j.jesp.2012.02.006

Stepanova, E.V., Bartholow, B.D., Saults, J.S., \& Friedman, R.S. (in press). Effects of exposure to alcohol-related cues on racial discrimination. European Journal of Social Psychology. doi: 10.1002/ejsp.2325

Stacy, A. W. (1995). Memory association and ambiguous cues in models of alcohol and marijuana use. Experimental and Clinical Psychopharmacology,3, 183-194. doi: $10.1037 / 1064-1297.3 .2 .183$

Stormo, K.J., Lang, A.R., \& Stritzke, W.G.K. (1997). Attributions about acquaintance rape: The 
role of alcohol and individual differences. Journal of Applied Social Psychology, 27, 279305. doi: 10.1111/j.1559-1816.1997.tb00633.x

Subra, B., Muller, D., Bègue, L., Bushman, B., \& Delmas, F. (2010). Automatic effects of alcohol and aggressive cues on aggressive thoughts and behaviors. Personality and Social Psychology Bulletin, 36(8), 1052-1057. doi:10.1177/0146167210374725.

Substance Abuse and Mental Health Services Administration (2015). 2015 National Survey on Drug Use and Health (NSDUH). Table 6.84B-Tobacco Product and Alcohol Use in Past Month among Persons Aged 18 to 22, by College Enrollment Status: Percentages, 2014 and 2015. Retrieved from: https://www.samhsa.gov/data/sites/default/files/NSDUHDetTabs-2015/NSDUH-DetTabs-2015/NSDUH-DetTabs-2015.htm\#tab6-84b.

Testa, M., Fillmore, M. T., Norris, J., Abbey, A., Curtin, J. J., Leonard, K. E., \& ... Hayman, L. J. (2006). Understanding alcohol expectancy effects: Revisiting the placebo condition. Alcoholism: Clinical and Experimental Research, 30(2), 339-348. doi:10.1111/j.1530-0277.2006.00039.x

Trafimow, D. (2003). Hypothesis testing and theory evaluation at the boundaries: Surprising insights from Bayes's theorem. Psychological Review, 110, 526-535. doi:10.1037=0033295x.110.3.526

Valentine, J. C., Aloe, A. M., \& Lau, T. S. (2015). Life after NHST: How to describe your data without "p-ing” everywhere. Basic and Applied Social Psychology, 37(5), 260-273. doi: $10.1080 / 01973533.2015 .1060240$

Vandiver, D. M., \& Dupalo, J. R. (2013). Factors that affect college students' perceptions of rape: What is the role of gender and other situational factors? International Journal of Offender Therapy and Comparative Criminology, 57(5), 592-612. doi:10.1177/0306624X12436797 
Wall, A. M., \& Schuller, R. A. (2000). Sexual assault and defendant/victim intoxication: Jurors' perceptions of guilt. Journal of Applied Social Psychology, 30, 253-274. doi:10.1111/j.1559-1816.2000.tb02315.x

Walters, M.L., Chen J., \& Breiding, M.J. (2013). The National Intimate Partner and Sexual Violence Survey (NISVS): 2010 Findings on Victimization by Sexual Orientation. Retrieved from the Centers for Disease Control and Prevention: http://www.cdc.gov/ViolencePrevention/pdf/NISVS_SOfindings.pdf

Wasserstein, R. L., \& Lazar, N. A. (2016, May). The ASA's statement on p -values: Context, process, and purpose. American Statistician. pp. 129-133. doi:10.1080/00031305.2016.1154108.

Wechsler, H., Molnar, B. E., Davenport, A. E., \& Baer, J. S. (1999). College alcohol use: A full or empty glass? Journal of American College Health, 47(6), 247 - 252. doi:

\section{$10.1080 / 07448489909595655$}

White, A., \& Hingson, R. (2014). The burden of alcohol use: Excessive alcohol consumption and related consequences among college students. Alcohol Research : Current Reviews, 35(2), 201-218.

Untied, A. S., Orchowski, L. M., Mastroleo, N., \& Gidycz, C. A. (2012). College students' social reactions to the victim in a hypothetical sexual assault scenario: The role of victim and perpetrator alcohol use. Violence and Victims, 27(6), 957-972. doi:10.1891/08866708.27.6.957 


\section{Footnotes}

${ }^{1}$ We are aware that Cronbach's $\alpha$ is below recommended .7 or .8 (Nunnally, 1967, 1978) for victim and perpetrator blame. However, reliability of .5 or .6 is sufficient for exploratory research, as stated in Nunnally's earliest work (1967). Since (a) recommended $\alpha$ levels are not based on empirical research and (b) deleting items to increase $\alpha$ is a questionable, though widely used practice (for review, see Cho \& Kim, 2015), we decided to report results as is.

${ }^{2}$ These items were intended to form subscales for each characters' sexual attraction toward the other. However, although the two items assessing Kevin's feelings for Jessica were modestly correlated $\left(r_{l}=.34\right)$, the two items assessing Jessica's feelings for Kevin were not correlated at all $\left(r_{2}=.11\right)$. Because these items were less pertinent to our primary hypotheses and were unreliable measures of the constructs they were designed to assess, these items were not further analyzed. Questions 13 and 14 were included for exploratory review of reactions to the vignette. The same reasoning holds for Study $2\left(r_{1}\right.$ $=.23$ and $\left.r_{2}=.19\right)$.

${ }^{3}$ The ethnic makeup of the participants in both studies was comparable to student demographics at the two universities. Male participants and first-year students were oversampled.

${ }^{4}$ SAMHSA data indicated that $58 \%$ of students reported consuming alcohol over the past month. Note that our prevalence data was based on reports of ever drinking, not drinking in the past month; however, when we calculated the percentage of students who reported drinking over the past month, estimates were still higher than $58 \%$ (but lower than we reported in the text). Wechsler et al. reported typical weekly drinking quantity of 5 drinks per week. 
Table 1

Ratings of Victim Blame and Perpetrator Blame as a Function of Picture Prime, Story Prime and Gender of Participants in Study 1

Victim Blame

\begin{tabular}{|c|c|c|c|c|c|c|c|c|c|}
\hline & \multicolumn{3}{|c|}{$\underline{\text { Alcohol ads condition }}$} & \multicolumn{3}{|c|}{$\underline{\text { Non-alcohol ads condition }}$} & \multicolumn{3}{|c|}{$\underline{\text { Total }}$} \\
\hline & Men & Women & Total & Men & Women & Total & Men & Women & Total \\
\hline Story prime & $M, S D$ & $M, S D$ & $M, S D$ & $M, S D$ & $M, S D$ & $M, S D$ & $M, S D$ & $M, S D$ & $M, S D$ \\
\hline Beer vignette & $3.21,1.16$ & $2.65,1.00$ & $2.95,1.11$ & $2.89,1.29$ & $2.52,1.07$ & $2.73,1.20$ & $3.05,1.22$ & $2.59,1.02$ & $2.84,1.15$ \\
\hline Coke vignette & $2.30,1.12$ & $2.53,1.19$ & $2.41,1.15$ & $2.72,1.14$ & $2.50,1.12$ & $2.61,1.12$ & $2.52,1.14$ & $2.52,1.14$ & $2.52,1.13$ \\
\hline Total & $2.78,1.22$ & $2.60,1.08$ & $2.70,1.15$ & $2.81,1.21$ & $2.51,1.08$ & $2.67,1.15$ & $2.80,1.21$ & $2.55,1.08$ & $2.68,1.15$ \\
\hline
\end{tabular}

Perpetrator Blame

\begin{tabular}{|c|c|c|c|c|c|c|c|c|c|}
\hline & \multicolumn{3}{|c|}{ Alcohol ads condition } & \multicolumn{3}{|c|}{ Non-alcohol ads condition } & \multicolumn{3}{|c|}{$\underline{\text { Total }}$} \\
\hline & Men & Women & Total & Men & Women & Total & Men & Women & Total \\
\hline Story prime & $M, S D$ & $M, S D$ & $M, S D$ & $M, S D$ & $M, S D$ & $M, S D$ & $M, S D$ & $M, S D$ & $M, S D$ \\
\hline Beer vignette & $6.53, .71$ & $6.61, .59$ & $6.56, .65$ & $6.53, .99$ & $6.77, .34$ & $6.64, .77$ & $6.53, .85$ & $6.68, .49$ & $6.60, .71$ \\
\hline Coke vignette & $6.74, .45$ & $6.65, .63$ & $6.70, .54$ & $6.61, .59$ & $6.83, .31$ & $6.72, .48$ & $6.68, .52$ & $6.75, .49$ & $6.71, .50$ \\
\hline Total & $6.63, .60$ & $6.63, .60$ & $6.63, .60$ & $6.57, .81$ & $6.80, .32$ & $6.68, .64$ & $6.60, .71$ & $6.72, .49$ & $6.65, .62$ \\
\hline
\end{tabular}

Note. $N=184, n=98$ (men) and $n=86$ (women). 
Table 2

Ratings of Victim Blame and Perpetrator Blame as a Function of Picture Prime, Story Prime and Gender of Participants in Study 2

\begin{tabular}{|c|c|c|c|c|c|c|c|c|c|}
\hline & \multicolumn{9}{|c|}{ Victim Blame } \\
\hline & \multicolumn{3}{|c|}{$\underline{\text { Alcohol ads condition }}$} & \multicolumn{3}{|c|}{$\underline{\text { Non-alcohol ads condition }}$} & \multicolumn{3}{|c|}{$\underline{\text { Total }}$} \\
\hline & Men & Women & Total & Men & Women & Total & Men & Women & Total \\
\hline Story prime & $M, S D$ & $M, S D$ & $M, S D$ & $M, S D$ & $M, S D$ & $M, S D$ & $M, S D$ & $M, S D$ & $M, S D$ \\
\hline Beer vignette & $2.63,1.31$ & $2.41,1.36$ & $2.52,1.33$ & $2.75,1.24$ & $1.89,1.05$ & $2.35,1.22$ & $2.69,1.27$ & $2.20,1.26$ & $2.45,1.29$ \\
\hline Coke vignette & $2.20,1.12$ & $2.03,1.07$ & $2.13,1.10$ & $2.55,1.25$ & $2.07,1.09$ & $2.34,1.20$ & $2.38,1.19$ & $2.05,1.08$ & $2.24,1.15$ \\
\hline Total & $2.43,1.24$ & $2.26,1.26$ & $2.35,1.23$ & $2.64,1.24$ & $1.99,1.07$ & $2.34,1.21$ & $2.53,1.24$ & $2.14,1.18$ & $2.35,1.23$ \\
\hline
\end{tabular}

Perpetrator Blame

\begin{tabular}{|c|c|c|c|c|c|c|c|c|c|}
\hline & \multicolumn{3}{|c|}{$\underline{\text { Alcohol ads condition }}$} & \multicolumn{3}{|c|}{ Non-alcohol ads condition } & \multicolumn{3}{|c|}{$\underline{\text { Total }}$} \\
\hline & Men & Women & Total & Men & Women & Total & Men & Women & Total \\
\hline Story prime & $M, S D$ & $M, S D$ & $M, S D$ & $M, S D$ & $M, S D$ & $M, S D$ & $M, S D$ & $M, S D$ & $M, S D$ \\
\hline Beer vignette & $6.51, .79$ & $6.61, .93$ & $6.56, .86$ & $6.50,1.02$ & $6.76, .51$ & $6.62, .83$ & $6.50, .89$ & $6.67, .79$ & $6.58, .85$ \\
\hline Coke vignette & $6.72, .54$ & $6.76, .58$ & $6.74, .55$ & $6.33,1.09$ & $6.61, .86$ & $6.45,1.00$ & $6.52, .88$ & $6.68, .74$ & $6.59, .82$ \\
\hline
\end{tabular}

Note. $N=421, n=225$ (men) and $n=196$ (women). 
Appendix A

Significance Tests for Study 1

\begin{tabular}{|c|c|c|c|c|c|}
\hline \multicolumn{6}{|c|}{ Victim Blame } \\
\hline Source & $d f$ & Mean Square & $F$ & $p$ & Partial Eta Squared \\
\hline Gender & 1 & 2.432 & 1.869 & .173 & .011 \\
\hline Picture Prime & 1 & .011 & .008 & .927 & .000 \\
\hline Story Prime & 1 & 4.152 & 3.190 & .076 & .018 \\
\hline Story Prime x Gender & 1 & 2.504 & 1.924 & .167 & .011 \\
\hline Story Prime x Picture Prime & 1 & 1.970 & 1.514 & .220 & .009 \\
\hline Picture Prime x Story Prime x Gender & 1 & 1.125 & .864 & .354 & .005 \\
\hline Error & 176 & 1.301 & & & \\
\hline
\end{tabular}

\begin{tabular}{|c|c|c|c|c|c|}
\hline \multicolumn{6}{|c|}{ Perpetrator Blame } \\
\hline Source & $d f$ & Mean Square & $F$ & $p$ & Partial Eta Squared \\
\hline Gender & 1 & .569 & 1.478 & .226 & .008 \\
\hline Picture Prime & 1 & .143 & .370 & .544 & .002 \\
\hline Story Prime & 1 & .460 & 1.196 & .276 & .007 \\
\hline Picture Prime x Gender & 1 & .615 & 1.596 & .208 & .009 \\
\hline Story Prime x Gender & 1 & .093 & .242 & .624 & .001 \\
\hline Story Prime x Picture Prime & 1 & .036 & .095 & .759 & .001 \\
\hline Picture Prime x Story Prime x Gender & 1 & .072 & .186 & .667 & .001 \\
\hline Error & 176 & .385 & & & \\
\hline
\end{tabular}


Appendix B

Significance Tests for Study 2

\begin{tabular}{|c|c|c|c|c|c|}
\hline \multicolumn{6}{|c|}{ Victim Blame } \\
\hline Source & $d f$ & Mean Square & $F$ & $p$ & Partial Eta Squared \\
\hline Gender & 1 & 19.321 & 13.281 & $<.001$ & .031 \\
\hline Picture Prime & 1 & .001 & .001 & .978 & .000 \\
\hline Story Prime & 1 & 4.290 & 2.949 & .087 & .007 \\
\hline Picture Prime x Gender & 1 & 5.622 & 3.865 & .050 & .009 \\
\hline Story Prime x Gender & 1 & 1.197 & .823 & .365 & .002 \\
\hline Story Prime x Picture Prime & 1 & 3.987 & 2.741 & .099 & .007 \\
\hline Picture Prime x Story Prime x Gender & 1 & .660 & .453 & .501 & .001 \\
\hline Error & 413 & 1.455 & & & \\
\hline \multicolumn{6}{|c|}{ Perpetrator Blame } \\
\hline Source & $d f$ & Mean Square & $F$ & $p$ & Partial Eta Squared \\
\hline Gender & 1 & 3.001 & 4.347 & .038 & .010 \\
\hline Picture Prime & 1 & 1.065 & 1.543 & .215 & .004 \\
\hline Story Prime & 1 & .014 & .020 & .887 & .000 \\
\hline Picture Prime x Gender & 1 & 1.046 & 1.515 & .219 & .004 \\
\hline Story Prime x Gender & 1 & .007 & .010 & .922 & .000 \\
\hline Story Prime x Picture Prime & 1 & 3.021 & 4.376 & .037 & .010 \\
\hline Picture Prime x Story Prime x Gender & 1 & .030 & .044 & .835 & .000 \\
\hline Error & 413 & .690 & & & \\
\hline
\end{tabular}

